\title{
Nitrogen Incorporation in the Biosynthetic Pathway of the Nitrogen-containing Polyketide, Pamamycin in Streptomyces alboniger
}

\author{
Makoto Hashimoto ${ }^{\dagger}$, Ikuko Kozone, Hiroshi Kawaide, Hiroshi Abe, Masahiro Natsume
}

Received: September 6, 2005 / Accepted: November 10, 2005

(C) Japan Antibiotics Research Association

\begin{abstract}
The biosynthetic pathway of pamamycin (1), a nitrogen-containing polyketide, was investigated using blocked mutants of Streptomyces alboniger. Hydroxy acids K (3), L (4) and S (5) were found in cultured materials of blocked mutants and the wild type strain, but no PM-ketone (2) was detected. Hydroxy acids 3, 4, 5 and de- $N$ methylhydroxy acid L (7) were converted into $\mathbf{1}$, but $\mathbf{2}$ nor de- $N$-methylpamamycin (6) were not. We also confirmed that $\mathbf{3}$ and $\mathbf{7}$ were converted into $\mathbf{4}$. These results showed that an amino group was introduced into the carbonyl group of 3 by transamination, and subsequent $\mathrm{N}$ methylation led to $\mathbf{4}$ in the pamamycin biosynthetic pathway. Quantitative analyses of hydroxy acid intermediates 3, 4, and 5, and pamamycin (1) suggested that transamination was the rate-determining step in pamamycin biosynthesis.
\end{abstract}

Keywords pamamycin, biosynthesis, transamination, polyketide

\section{Introduction}

Pamamycin-607 (1; MW 607; $\mathrm{R}_{1}, \mathrm{R}_{2}, \mathrm{R}_{3}, \mathrm{R}_{4}=\mathrm{CH}_{3}, \mathrm{R}_{5}=\mathrm{H}$ ) (Fig. 1) has been isolated from Streptomyces alboniger as an autoregulator inducing aerial mycelium formation in an aerial mycelium-less mutant [1 3]. In previous reports, we isolated 14 pamamycin homologues with different alkyl substituents at $\mathrm{R}_{1} \sim \mathrm{R}_{5}$ with MW ranging from 593 to 649 , prepared some degradation products of pamamycin-607, and discussed structure-activity relationships [4 6]. We also showed that exogenous pamamycin-607 restored or stimulated aerial mycelium formation in many Streptomyces species, indicating that pamamycin-607 acts in a common regulatory system for aerial mycelium formation in Streptomyces spp. [7].

The structure of pamamycin consists of a unique sixteenmembered macrodiolide with a dimethylamino groupbearing side chain. We recently showed using feeding experiments with ${ }^{13} \mathrm{C}$ - and ${ }^{15} \mathrm{~N}$-labeled compounds that the carbon skeleton of pamamycin-607 was derived from 6 acetate, 4 propionate and 3 succinate units via a polyketide pathway, and a nitrogen atom was incorporated from an $\alpha$ amino group of an amino acid into a carbonyl group by transamination reaction [8].

The macrodiolide structure of pamamycin suggested that the carbon skeleton of $\mathbf{1}$ was assembled from two hydroxy acids $\mathrm{K}(\mathbf{3})$ and $\mathrm{S}(\mathbf{5})$. It is still unknown when the nitrogen atom is introduced into the carbon skeleton. We are interested in investigating nitrogen incorporation during biosynthesis of pamamycin because the dimethylamino group of pamamycin-607 is indispensable for aerial
M. Natsume (Corresponding author), M. Hashimoto ${ }^{\dagger}, \mathbf{H}$. Kawaide, H. Abe: Department of Plant Protection, United Graduate School of Agricultural Science, Tokyo University of Agriculture and Technology, Saiwai-cho, Fuchu, Tokyo 183-8509, Japan E-mail: natsume@cc.tuat.ac.jp
I. Kozone: Department of Biotechnology and Life Science, Tokyo University of Agriculture and Technology, Naka-cho, Koganei, Tokyo 184-8588, Japan

$\dagger$ Present address: Research Institute of Pharmaceutical Sciences, Musashino University, Shinmachi, Nishitokyo, Tokyo 202-8585, Japan 
mycelium-inducing activity [6] and nitrogen-containing polyketides are rare.

We suggest two pathways for the biosynthesis of $\mathbf{1}$ from two hydroxy acids $\mathbf{3}$ and $\mathbf{5}$ (Fig. 1). One pathway involves the formation of a keto-macrodiolide intermediate (PMketone, $\mathbf{2}$ ) by condensation of $\mathbf{3}$ and $\mathbf{5}$, then the nitrogen atom is introduced into the carbon skeleton by transamination, and $N$-methylation leads to 1 . Isolation of de- $N$-methylpamamycins (6) from cultured materials of $S$. alboniger $[9,10]$ supported this hypothesis. The other pathway would involve acceptance of a nitrogen atom by the larger hydroxy acid $\mathbf{3}$, and then $N$-methylation occurs to produce hydroxy acid L (4) before formation of the macrodiolide ring.

In this paper, we describe transamination and condensation steps in pamamycin biosynthesis by investigating biosynthetic intermediates of pamamycin in cultured materials of blocked mutants of $S$. alboniger, and report bioconversion experiments with these compounds. The $N$-methylation step was also investigated using bioconversion experiments of de- $N$-methylpamamycin (6) and de- $N$-methylhydroxy acid L (7). The rate-determining step of pamamycin production was discussed by quantitative analyses of biosynthetic intermediates and pamamycin (1) in cultured materials of the wild type strain.

\section{Results}

\section{Isolation of Blocked Mutants}

Mutants producing no or little pamamycin were screened for two reasons; strains in which mutation occur in the later step of the biosynthetic pathway would accumulate intermediates, and strains in which the earlier biosynthetic step is disturbed would be used for conversion experiments of possible intermediates into pamamycin.

From 40,000 colonies obtained by $N$-methyl- $N^{\prime}$-nitro- $N$ nitrosoguanidine (NTG) mutation, 400 colonies which formed no or little aerial mycelia were selected. These mutants were tested for their responses to pamamycin-607, and 20 strains whose aerial mycelium formation was restored or stimulated by pamamycin-607 were further selected (Fig. 2). Production of pamamycin by these 20 strains was then determined by liquid chromatographyelectrospray ionization mass spectrometry (LC-ESI-MS) analysis. Among them, strains 188 and 202 showed lower pamamycin production than that of the wild type strain; production of total pamamycin and pamamycin-607 were 5.7 and $1.0 \mu \mathrm{g} / \mathrm{ml}$ in strain 188 , and 19 and $1.0 \mu \mathrm{g} / \mathrm{ml}$ in strain 202, respectively; whereas the wild type strain produced $40 \mu \mathrm{g} / \mathrm{ml}$ total pamamycin and $6.0 \mu \mathrm{g} / \mathrm{ml}$ pamamycin-607.

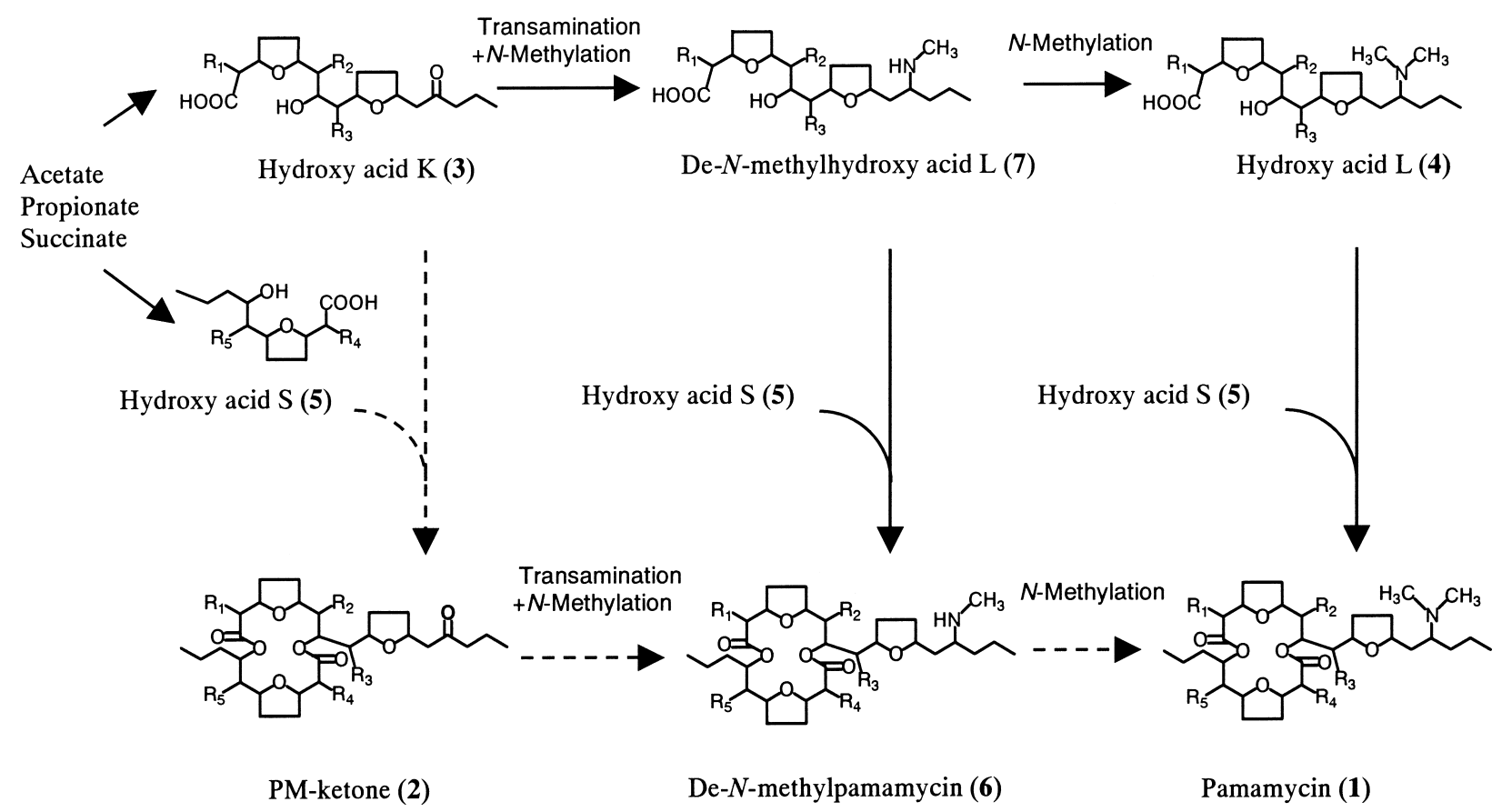

Fig. 1 Structure and proposed biosynthetic pathway of pamamycin. 


\section{Biosynthetic Intermediates Produced by Mutants and the Wild Type Strain}

Presence of possible intermediates of pamamycin, PMketone (2), hydroxy acids K (3), L (4) and S (5), were investigated in the cultured materials of two mutants, strains 188 and 202, and amounts of these compounds were compared with those of the wild type strain (Fig. 3). In

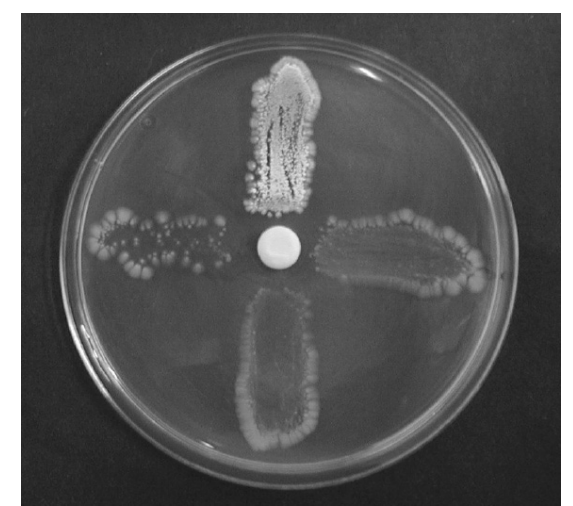

Fig. 2 Response of aerial mycelium-deficient mutants to pamamycin.

Paper disk containing pamamycin-607 was placed in the center of agar medium and 4 mutants were streaked radially around the disk. The upper mutant restored the formation of white aerial mycelia in response to pamamycin-607 but other 3 mutants remained in bald. strain 188, $\mathbf{3}$ and $\mathbf{5}$ were not detected, and $\mathbf{4}$ was produced at one-fourth the amount produced by the wild type strain. In strain $202, \mathbf{5}$ decreased to one-tenth of wild type strain, but 3 and 4 increased 2.9 and 3.8 folds more than the wild type strain. On the other hand, no 2 was detected in both blocked mutants and the wild type strain (Fig. 3).

These results suggested that $\mathbf{1}$ was not synthesized via $\mathbf{2}$ but by condensation of $\mathbf{4}$ and $\mathbf{5}$, and the nitrogen atom of $\mathbf{1}$ was introduced to the carbonyl group of $\mathbf{3}$ before condensation with $\mathbf{5}$. These results also suggested that mutation in strain 188 occurred during the earlier steps of the biosynthetic pathway that were common to hydroxy acids $\mathbf{4}$ and $\mathbf{5}$; and in strain 202, mutation occurred during biosynthesis of hydroxy acid $\mathbf{5}$.

\section{Bioconversion of Hydroxy Acids $(3,4,5)$ and PM-ketone} (2) to Pamamycin (1)

Bioconversion experiment of $\mathbf{5}$ to $\mathbf{1}$ was performed with strain 202. Non-labeled and ${ }^{13} \mathrm{C}$-labeled $\mathbf{5}$ were prepared by alkaline hydrolysis of non-labeled and ${ }^{13} \mathrm{C}$-labeled pamamycin (1), respectively. ${ }^{13} \mathrm{C}$-Labeled $\mathbf{1}$ was obtained by a feeding experiment with $\left[2-{ }^{13} \mathrm{C}\right]$ acetate as described in a previous paper [8]. Hydroxy acid 5 was used as a mixture of homologues, and incubated for 60 hours. Pamamycin fraction obtained from mycelia was analyzed using LC-ESI-MS, and intensities of the molecular ion $(\mathrm{m} / \mathrm{z}$ $608)$ and its isotope peaks of pamamycin-607 were
Hydroxy acid K (3)
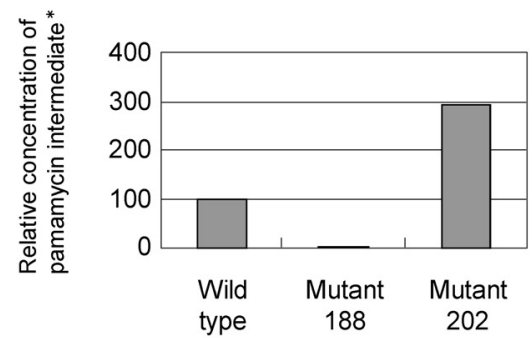

Hydroxy acid S (5)
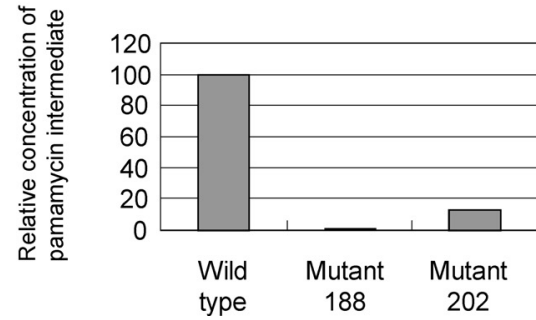

Hydroxy acid L (4)

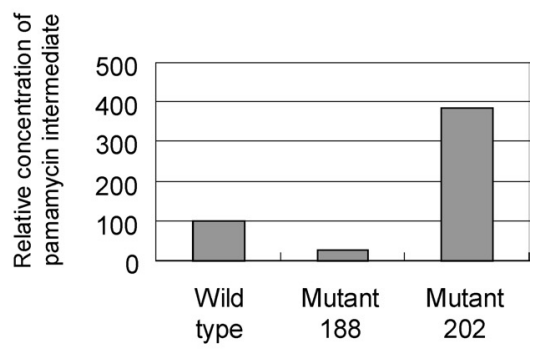

PM-ketone (2)

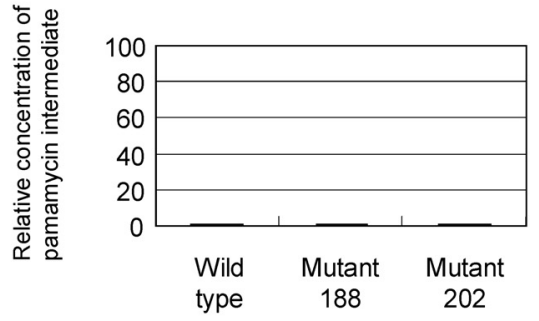

Fig. 3 Analysis of intermediates accumulated in blocked mutants during pamamycin biosynthesis.

* Production of intermediates by the wild type strain were defined as 100.

Detection limits were $18,2,2$, and 0.5 ng for hydroxy acids $\mathrm{K}, \mathrm{L}, \mathrm{S}$, and PM-ketone, respectively. 
measured.

In the feeding experiment with ${ }^{13} \mathrm{C}$-labeled $\mathbf{5}$, ratios of isotope peaks $(\mathrm{m} / z 610(\mathrm{M}+\mathrm{H}+2), 611(\mathrm{M}+\mathrm{H}+3)$ and $612(\mathrm{M}+\mathrm{H}+4))$ in the molecular ion cluster were higher than those with administration of non-labeled $\mathbf{5}$ (Table 1). These results showed that hydroxy acid $\mathbf{5}$ was incorporated into 1.

Bioconversions of 3, $\mathbf{4}$ and $\mathbf{2}$ to $\mathbf{1}$ were performed with strain 188 in a similar manner as in the feeding experiment with $\mathbf{5}$ in strain 202. Hydroxy acids $\mathbf{3}$ and $\mathbf{4}$ were prepared by alkaline hydrolysis of $\mathbf{2}$ and $\mathbf{1}$, respectively, hence each contained comparable amounts of 5. PM-ketone (2) was derived from 1 by permanganate oxidation [11].

Addition of ${ }^{13} \mathrm{C}$-labeled 3 or $\mathbf{4}$ containing 5 increased intensities of isotope peaks with $m / z 610(\mathrm{M}+\mathrm{H}+2)$ to 614 $(\mathrm{M}+\mathrm{H}+6)$ in the molecular ion cluster as compared with those of non-labeled precursors, respectively (Table 1). These results showed that hydoxy acids $\mathbf{3}$ and $\mathbf{4}$ were incorporated into 1 since intensity of isotope peaks with larger $\mathrm{m} / \mathrm{z}$ values increased compared with results of sole administration of ${ }^{13} \mathrm{C}$-labeled 5 . In the feeding experiment with $\mathbf{3}+\mathbf{5}$, compound $\mathbf{2}$ was not detected in cultured materials.

Feeding experiments with ${ }^{13} \mathrm{C}$-labeled and non-labeled 2 showed no differences in intensity for each isotope peak compared with that of total molecular ion peaks (Table 1), although ${ }^{13} \mathrm{C}$-labeled 2 was recovered from the mycelial extract (data not shown), suggesting that $\mathbf{2}$ was incorporated into mycelia, but was not converted into $\mathbf{1}$.

\section{Bioconversion of De- $N$-methylpamamycin (6) and De- $N$ - methylhydroxy acid L (7) to Pamamycin (1)}

To confirm that a nitrogen atom was introduced into $\mathbf{3}$, feeding experiments with de- $N$-methylpamamycin (6) and de- $N$-methylhydroxy acid L (7) were performed in strain 188. De- $N$-methylpamamycin 6 used for the experiment was purified from cultured materials of $S$. alboniger as reported previously $[9,10]$, and a mixture of 7 and 5 was prepared by alkaline hydrolysis of $\mathbf{6}$.

Feeding experiments with ${ }^{13} \mathrm{C}$-labeled and non-labeled $\mathbf{6}$ showed no differences in relative intensity of peaks in the molecular ion cluster (Table 1), although ${ }^{13} \mathrm{C}$-labeled 6 was detected in the mycelial extract (data not shown), suggesting that $\mathbf{6}$ was transported into mycelia but was not converted into $\mathbf{1}$ as was the case with $\mathbf{2}$.

Addition of ${ }^{13} \mathrm{C}$-labeled $\mathbf{7}$ with $\mathbf{5}$ increased intensities of isotope peaks with $m / z 610(\mathrm{M}+\mathrm{H}+2)$ to $612(\mathrm{M}+\mathrm{H}+4)$ in the molecular ion cluster compared with those with nonlabeled precursors (Table 1). These results showed that 7 was incorporated into $1 .{ }^{13} \mathrm{C}$-labeled $\mathbf{7}$ with $\mathbf{5}$ also increased intensities of isotope peaks of de- $N$-methylpamamycin (6) in cultured materials (data not shown).

\section{Bioconversion of Hydroxy Acid K (3) and De- $\mathrm{N}$ -} methylhydroxy Acid L (7) to Hydroxy Acid L (4)

In feeding experiments with $\mathbf{3}$ and $\mathbf{5}$ or $\mathbf{7}$ and $\mathbf{5}$,

Table 1 Effects of non-labeled and ${ }^{13} \mathrm{C}$-labeled precursors on relative intensity of molecular ion peak and isotope peaks of pamamycin-607

Ratio of molecular ion peak and isotope peaks (\%) in the molecular ion cluster ${ }^{\mathrm{a}}$

\begin{tabular}{|c|c|c|c|c|c|c|c|c|c|}
\hline \multicolumn{2}{|c|}{ Precursors } & \multirow[t]{2}{*}{ Strains } & \multicolumn{7}{|c|}{$\mathrm{m} / \mathrm{z}$} \\
\hline & & & 608 & 609 & 610 & 611 & 612 & 613 & 614 \\
\hline \multirow[t]{2}{*}{5} & Non-labeled & \multirow{2}{*}{ Mutant 202} & 72 & 24 & 4 & $-^{\mathrm{b}}$ & - & - & - \\
\hline & ${ }^{13} \mathrm{C}$-labeled & & 65 & 24 & 7 & 2 & 1 & - & - \\
\hline \multirow[t]{2}{*}{$3+5$} & Non-labeled & \multirow{2}{*}{ Mutant 188} & 70 & 25 & 5 & - & - & - & - \\
\hline & ${ }^{13} \mathrm{C}$-labeled & & 54 & 25 & 11 & 5 & 2 & 2 & 1 \\
\hline \multirow[t]{2}{*}{$4+5$} & Non-labeled & \multirow{2}{*}{ Mutant 188} & 69 & 26 & 5 & - & - & - & - \\
\hline & ${ }^{13} \mathrm{C}$-labeled & & 52 & 26 & 11 & 5 & 3 & 2 & 1 \\
\hline \multirow[t]{2}{*}{2} & Non-labeled & \multirow{2}{*}{ Mutant 188} & 71 & 24 & 5 & - & - & - & - \\
\hline & ${ }^{13} \mathrm{C}$-labeled & & 70 & 25 & 5 & - & - & - & - \\
\hline \multirow[t]{2}{*}{6} & Non-labeled & \multirow{2}{*}{ Mutant 188} & 70 & 26 & 4 & - & - & - & - \\
\hline & ${ }^{13} \mathrm{C}$-labeled & & 71 & 24 & 5 & - & - & - & - \\
\hline \multirow[t]{2}{*}{$7+5$} & Non-labeled & \multirow{2}{*}{ Mutant 188} & 71 & 25 & 4 & - & - & - & - \\
\hline & ${ }^{13} \mathrm{C}$-labeled & & 60 & 27 & 9 & 3 & 1 & - & - \\
\hline
\end{tabular}

a Sum of peak intensity is $100 \% . \quad{ }^{b}<1 \%$. 
Table 2 Effects of ${ }^{13} \mathrm{C}$-labeled precursors on relative intensity of molecular ion peak and isotope peaks of hydroxy acid $\mathrm{L}$ with MW 413

Ratio of molecular ion peak and isotope peaks $(\%)$ in the molecular ion cluster ${ }^{\mathrm{a}}$

\begin{tabular}{|c|c|c|c|c|c|c|c|}
\hline \multicolumn{2}{|c|}{ Precursors } & \multirow[t]{2}{*}{ Strains } & \multicolumn{5}{|c|}{$m / z$} \\
\hline & & & 414 & 415 & 416 & 417 & 418 \\
\hline \multirow[t]{2}{*}{$3+5$} & Non-labeled & \multirow{2}{*}{ Mutant 188} & 84 & 14 & 2 & $-^{\mathrm{b}}$ & - \\
\hline & ${ }^{13} \mathrm{C}$-labeled & & 70 & 15 & 8 & 7 & - \\
\hline \multirow[t]{2}{*}{$7+5$} & Non-labeled & \multirow{2}{*}{ Mutant 188} & 84 & 14 & 2 & - & - \\
\hline & ${ }^{13} \mathrm{C}$-labeled & & 76 & 18 & 4 & 2 & - \\
\hline
\end{tabular}

a Sum of peak intensity is $100 \% . \quad b<1 \%$.

Table 3 Production of pamamycin and its intermediates by wild type strains of $S$. alboniger

\begin{tabular}{lcc}
\hline & \multicolumn{2}{c}{ Production of pamamycin and its intermediates } \\
\cline { 2 - 3 } Compound & $\mu \mathrm{g} / \mathrm{ml}$ & $\mathrm{nmol} / \mathrm{ml}$ \\
\hline Hydroxy acid $\mathrm{K}(\mathbf{3})$ & 0.62 & 1.62 \\
Hydroxy acid L (4) & 0.27 & 0.66 \\
Hydroxy acid S (5) & 0.63 & 2.74 \\
Pamamycin (1) & 40.0 & 65.9 \\
\hline
\end{tabular}

incorporation of $\mathbf{3}$ or 7 into hydroxy acid L (4) fraction was also analyzed together with the pamamycin fraction.

Addition of ${ }^{13} \mathrm{C}$-labeled 3 or 7 increased intensities of isotope peaks with $\mathrm{m} / \mathrm{z} 416(\mathrm{M}+\mathrm{H}+2)$ and $417(\mathrm{M}+\mathrm{H}+3)$ of hydroxy acid L with MW $413\left(4 ; \mathrm{R}_{1}, \mathrm{R}_{2}, \mathrm{R}_{3}=\mathrm{CH}_{3}\right)$ which is a constituent of pamamycin-607 compared with those of non-labeled precursors (Table 2). These results showed that hydroxy acids $\mathbf{3}$ and 7 were incorporated into $\mathbf{4}$, confirming that $\mathbf{1}$ was biosynthesized from $\mathbf{3}$ via $\mathbf{7}$ and $\mathbf{4}$.

\section{Quantitative Analysis of Hydroxy Acid Intermediates}

Hydroxy acids which are precursors of pamamycin in cultured materials of the wild type strain were quantified by LC-ESI-MS analysis when pamamycin production reached to the maximum. The authentic hydroxy acid $\mathrm{K}(\mathbf{3} ; \mathrm{MW}$ 384; $\mathrm{R}_{1}, \mathrm{R}_{2}, \mathrm{R}_{3}=\mathrm{CH}_{3}$ ), hydroxy acid $\mathrm{L}$ (4; $\mathrm{MW} 413 ; \mathrm{R}_{1}, \mathrm{R}_{2}$,

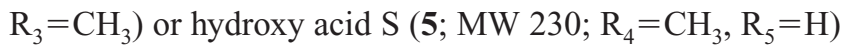
were obtained from the hydrolysate of the mixture of pamamycin homologues (1), and from PM-ketone (2) by preparative HPLC, respectively. As a result, the molar ratio of 3, 4, 5 and $\mathbf{1}$ was $5: 2: 8: 200$ (Table 3).

\section{Discussion}

Biosynthetic intermediates of pamamycin, hydroxy acids $\mathrm{K}$ (3), L (4), and S (5) were obtained from cultured materials of mutants and the wild type strain of $S$. alboniger, but the macrodiolide without nitrogen, PM-ketone (2) was not detected. The detected hydroxy acids, 3, 4 and $\mathbf{5}$ and de- $N$ methylhydroxy acid L (7) were incorporated into pamamycin (1), and hydroxy acids $\mathbf{3}$ and $\mathbf{7}$ were also converted into hydroxy acid 4. However, there was no evidence that $\mathbf{2}$ or de- $N$-methylpamamycin (6) were converted to $\mathbf{1}$, and $\mathbf{2}$ was not detected by conversion of hydroxy acids $\mathbf{3}$ and $\mathbf{5}$. These data showed that a nitrogen atom was introduced into the carbonyl group of hydroxy acid K (3) to yield hydroxy acid L (4), and then hydroxy acid $\mathrm{L}$ was condensed with hydroxy acid $\mathrm{S}(\mathbf{5})$ to produce pamamycin (1).

Quantitative analysis of hydroxy acids 3, 4 and 5 and pamamycin (1) suggested that the rate-determining step of pamamycin biosynthesis was a transamination reaction, because accumulation of hydroxy acid L (4) was smaller than hydroxy acids K (3) or S (5), and that of pamamycin was $25 \sim 100$ times larger than hydroxy acid L. These results showed that the produced hydroxy acid L immediately converted to pamamycin. This regulatory mechanism of pamamycin production is reasonable because introduction of a nitrogen atom has been reported to be essential for aerial mycelium-inducing activity $[6,10]$.

In some polyketide compounds, the nitrogen-containing unit is incorporated during biosynthesis [12]: the starter unit of tetracyclines is malonamyl-CoA. Rifamycins are biosynthesized from 3-amino-5-hydroxybenzoic acid. Thiazole compound derived from cysteine is the starter unit of epothilones. During biosynthesis of tacrolimus and rapamaycin, elongation of the polyketide chain is 
terminated by amidation with the nitrogen-containing unit, pipecolic acid. However, only one example reported that a nitrogen atom was introduced into the carbonyl group of a polyketide carbon skeleton, which is the dimethylamino group at C-4 of tetracyclines [13]. Pamamycin is the second example of this type.

The nitrogen atom contributes to expression of various biological activities, which are disclosed by numerous examples of alkaloids and synthetic medicinal and agricultural chemicals. Polyketides are an important group of secondary metabolites including various antibiotics, immunosuppressants, and anticancer agents. Introduction of nitrogen into polyketides will expand potentials of polyketide modifications. There are detailed studies on oxidation of C-6 $[14,15]$, and chlorination at C-7 [16] in post-PKS tailoring steps of tetracycline biosynthesis. However, there is little information on the transamination reaction [17].

The gene encoding the transamination reaction during pamamycin biosynthesis will serve as a new and powerful tool for combinatorial chemistry in polyketides. Molecular biological research of nonactin which consists of stereoisomeric homologues of hydroxy acid $\mathrm{S}$ in pamamycin, was carried by Priestley et al. [18] and Shen et al. [19]. We postulate that the homologue of nons gene, which encodes the enzyme catalyzing the formation of a tetrahydrofuran ring of the constituent hydroxy acid of nonactin, exists in the pamamycin biosynthetic gene cluster. We are now attempting to clone the gene cluster, and to determine the gene responsible for the transamination reaction.

\section{Experimental}

\section{General}

${ }^{13} \mathrm{C}$-NMR spectra were obtained with a JEOL JNM A-600 spectrometer at $150 \mathrm{MHz}$ in acetone- $d_{6}$ with an equimolar amount of $\mathrm{CF}_{3} \mathrm{COOD}$. GC-MS analyses were performed with a JEOL SX-102 A spectrometer. ESI mass spectral data were measured on a JEOLJMS-T100LC AccuTOF mass spectrometer.

\section{Strain and Media}

S. alboniger NBRC 12738 and its blocked mutants, strains 188 and 202, which were derived from the wild type strain by $N$-methyl- $N^{\prime}$-nitro- $N$-nitrosoguanidine (NTG) treatment, were used in this study. These strains were maintained on a Hickey and Tresner's agar (HTA) medium [20].

Medium for pamamycin production and bioconversion experiments contained maltose monohydrate $15.0 \mathrm{~g}$, yeast extract (Oriental Yeast Co. Ltd.) $3.0 \mathrm{~g}$, polypeptone S (Wako Pure Chemical Industries Ltd.) $10.0 \mathrm{~g}, \mathrm{NaCl} 3.0 \mathrm{~g}$, and $\mathrm{CaCO}_{3} 2.0 \mathrm{~g}$ in 1 liter distilled water.

\section{Mutagenesis}

Spores produced by S. alboniger NBRC12738 on ISS agar medium (ISP-4) were scraped off, and suspended in $50 \mathrm{mM}$ Tris-HCl ( $\mathrm{pH}$ 8.0) buffer containing 1\% Tween 80. The spore suspension was filtered through No. 2 filter paper and was diluted with the same buffer $\left(1 \times 10^{5}\right.$ spores $\left./ \mathrm{ml}\right)$. The diluted spore suspension was then treated with NTG at $1 \mathrm{mg} / \mathrm{ml}$, and kept standing at $28^{\circ} \mathrm{C}$ for 1 hour. The treated spore suspension was plated onto HTA medium $\left(2 \times 10^{3}\right.$ spores $/ 9 \mathrm{~cm}$ i.d. Petri dish), and incubated at $28^{\circ} \mathrm{C}$. After 7 days, colonies in which no or few aerial mycelia formed were transplanted to agar slants. This treatment resulted in a survival rate of $c a .1 \%$.

\section{Selection of Blocked Mutants During Pamamycin Biosynthesis}

Response of mutants to pamamycin-607 was examined by the paper disc method. In brief, 4 mutants were radially streaked on HTA medium in a Petri dish $(9 \mathrm{~cm}$ i.d.), and paper disc containing $10 \mu \mathrm{g}$ pamamycin mixture (pamamycin-607 content: 15\%) was placed in the center. Plates were incubated at $28^{\circ} \mathrm{C}$ for 7 days, and mutants that restored or stimulated aerial mycelium formation were selected.

Pamamycin production by selected mutants was estimated from the peak area of total ion chromatogram obtained by LC-ESI-MS using pamamycin-607 as standard. Mutants were inoculated into a 500-ml Sakaguchi flask containing $100 \mathrm{ml}$ of the production medium. The flask was placed on a reciprocal shaker (150 strokes/minute) for 6 days at $28^{\circ} \mathrm{C}$. Mycelia were collected from cultured broth by filtration, and were treated with acetone and then with EtOAc to obtain the extract. The EtOAc extract was dissolved in $\mathrm{MeOH}$, and was analyzed by LC-ESI-MS as described in the following section.

\section{LC-ESI-MS Analysis of Pamamycin and Biosynthetic Intermediates}

Production and isotopic composition of pamamycin and biosynthetic intermediates were analyzed as follows. LC conditions were: column, Develosil ODS-UG5 $(2.0 \mathrm{~mm}$ i.d. $\times 150 \mathrm{~mm}$; Nomura Chemical Co. Ltd.); solvent system, $90 \%$ aq. $\mathrm{MeOH}$ containing $0.2 \% \mathrm{NH}_{4} \mathrm{OAc}$ for pamamycin (1) and PM-ketone (2) or $\mathrm{MeOH}-0.1 \% \mathrm{HCOOH}(3: 2)$ for hydroxy acids $3,4,5,7$; flow rate, $0.2 \mathrm{ml} /$ minute; column oven temp., $25^{\circ} \mathrm{C}$. MS conditions were: detection mode, ESI positive mode; needle voltage, $1500 \mathrm{~V}$; orifice 1 
voltage, $49 \sim 51 \mathrm{~V}$; ringlens voltage, $9 \sim 13 \mathrm{~V}$; desolvation temp., $250^{\circ} \mathrm{C}$; orifice temp., $80^{\circ} \mathrm{C}$.

\section{Bioconversion of the Possible Intermediates}

Mutants were inoculated into $100 \mathrm{ml}$ of the production medium in a 500-ml Sakaguchi flask, and the flask was placed on a reciprocal shaker $(150$ strokes/minute $)$ at $28^{\circ} \mathrm{C}$ for 72 hours. This seed culture $(3 \mathrm{ml})$ was transferred to $500-\mathrm{ml} \mathrm{Sakaguchi}$ flasks, each containing $100 \mathrm{ml}$ of the same medium, and the flasks were incubated on a reciprocal shaker under the same conditions. Twelve hours after inoculation, substrate was added to each flask, and cultivation continued for an additional 60 hours. Compound 2, 5 or $\mathbf{6}$ was added as $\mathrm{MeOH}$ solution $(1.0 \mathrm{mg} / 0.5 \mathrm{ml})$ and 3, 4 or 7 was added as the mixture with 5 at the same concentration as mixture. Extraction and analysis of the converted products, pamamycin (1) or hydroxy acid L (4), were performed as mentioned above. Ratios of molecular ion peak and isotope peaks in the molecular ion cluster were calculated from results of $3 \sim 6$ runs of LC-ESI-MS analysis.

\section{Production of Intermediates Produced by Two Mutants and the Wild Type Strain}

Pamamycin intermediates were analyzed by LC-ESI-MS using 120-hour cultured material. PM-ketone (2) fraction was obtained from mycelia with EtOAc extraction similarly to $\mathbf{1}$. The $\mathbf{3}, \mathbf{4}$ and $\mathbf{5}$ homologue fractions were obtained from filtrate and mycelia.

\section{Preparation of Authentic Compounds for LC-MS Analysis and Substrate for Bioconversion}

PM-ketone (2)

PM-ketone (2) was prepared by permanganate oxidation [11] of 1 (composition of homologues, 607:621:635: $649=1: 3: 2: 1$ ). Potassium permanganate $(34 \mathrm{mg}, 0.22$ mmol) was added to a solution of $\mathbf{1}(4.3 \mathrm{mg}, 0.0071 \mathrm{mmol})$ in $t$ - $\mathrm{BuOH}-\mathrm{H}_{2} \mathrm{O}(1: 1,10 \mathrm{ml})$, and the solution was stirred for 2 hours at room temperature. The reaction mixture was filtered through celite, and this filtrate was treated with EtOAc after being adjusted to $\mathrm{pH}$ 8. The EtOAc extract was concentrated in vacuo and was applied to a Sep-Pak Plus silica cartridge. Compound 2 was eluted with EtOAc from the cartridge to separate from 1 ( $2.6 \mathrm{mg}$; yield, $64 \%)$. The structure of 2 was confirmed by disappearance of $\mathrm{N}-\mathrm{CH}_{3}$ signals in ${ }^{1} \mathrm{H}$ - and ${ }^{13} \mathrm{C}$-NMR spectra and LC-ESI-MS $(\mathrm{m} / \mathrm{z}$ 579, 593, $607621[\mathrm{M}+\mathrm{H}]^{+}$and $m / z 596,610,624,638$ $\left[\mathrm{M}+\mathrm{NH}_{4}\right]^{+}$). This obtained fraction was used for bioconversion of $\mathbf{2}$ to $\mathbf{1}$.

${ }^{13} \mathrm{C}$-Labeled 2 was prepared from ${ }^{13} \mathrm{C}$-labeled $\mathbf{1}$ in a similar manner as described above. ${ }^{13} \mathrm{C}$-labeled $\mathbf{1}$ was obtained by a feeding experiment of $\left[2-{ }^{13} \mathrm{C}\right]$ acetate in $S$. alboniger as previously described [8].

Hydroxy acid L (4) and S (5)

Hydroxy acid L (4) and S (5) were prepared by alkaline hydrolysis of 1 [21]. A solution of $1(8.8 \mathrm{mg}, 0.014 \mathrm{mmol})$ and potassium hydroxide $(3.36 \mathrm{~g}, 60 \mathrm{mmol})$ in ethanol $\mathrm{H}_{2} \mathrm{O}(8: 2,20 \mathrm{ml})$ was refluxed for 16 hours. The reaction mixture was cooled, and was extracted three times with $\mathrm{CH}_{2} \mathrm{Cl}_{2}(50 \mathrm{ml})$ after being adjusted to $\mathrm{pH}$ 6. The aqueous residue was then extracted three times with $\mathrm{CH}_{2} \mathrm{Cl}_{2}(50 \mathrm{ml})$ at $\mathrm{pH}$ 3. These $\mathrm{CH}_{2} \mathrm{Cl}_{2}$ extracts were combined, and concentrated in vacuo to obtain $\mathbf{4}$ and $\mathbf{5}$. This crude extract was used for bioconversion of $\mathbf{4}$ and $\mathbf{5}$ to $\mathbf{1}$.

To confirm the structures $\mathbf{4}$ and $\mathbf{5}$, the crude extract was methylated with diazomethane, and was analyzed by GCMS (column, DB-1 $(0.25 \mathrm{~mm}$ i.d. $\times 15 \mathrm{~m}$, film thickness 0.1 $\mu \mathrm{m}, \mathrm{J} \& \mathrm{~W}$ Scientific); inlet temp., $250^{\circ} \mathrm{C}$; chamber temp., $250^{\circ} \mathrm{C}$; column temp.: $50^{\circ} \mathrm{C}$ for 1 minute, $50^{\circ} \mathrm{C} /$ minute to $150^{\circ} \mathrm{C}, 16^{\circ} \mathrm{C} /$ minute to $280^{\circ} \mathrm{C}, 280^{\circ} \mathrm{C}$ for 5 minutes.) $[4,5]$. The extract contained hydroxy acid L (4) with MWs 413, 427 and 441, and hydroxy acid S (5) with MWs 230, 244 and 258. Proportion of hydroxy acid L with MW 413 (4; $\mathrm{R}_{1}, \mathrm{R}_{2}, \mathrm{R}_{3}=\mathrm{CH}_{3}$ ), which is component of pamamycin-607 [6], was $20 \%$ of total hydroxy acid $\mathrm{L}$, and that of hydroxy acid S with MW $230\left(\mathbf{5} ; \mathrm{R}_{4}=\mathrm{CH}_{3}, \mathrm{R}_{5}=\mathrm{H}\right)$ was $15 \%$ of total hydroxy acid $\mathrm{S}$. This mixture was used for bioconversion of 4 and 5 to 1 .

Hydroxy acids $\mathbf{4}$ and $\mathbf{5}$ were separated by preparative TLC $\left(\mathrm{CHCl}_{3}-\mathrm{MeOH}(9: 1)\right.$ ), and gave 4 (Rf value, $0 \sim$ $0.20 ; 3.2 \mathrm{mg} ; 53 \%$ ) and 5 (Rf value, $0.35 \sim 0.60 ; 2.6 \mathrm{mg}$; $78 \%$ ). Purified 5 was used for bioconversion to $\mathbf{1}$ with strain 202. These obtained fractions were used as reference compounds for analyzing $\mathbf{4}$ or $\mathbf{5}$ in cultured materials, and in products of bioconversion experiment of $\mathbf{5}$. The authentic hydroxy acid L with MW $413\left(4 ; \mathrm{R}_{1}, \mathrm{R}_{2}, \mathrm{R}_{3}=\mathrm{CH}_{3}\right)$ or hydroxy acid S with MW $230\left(\mathbf{5} ; \mathrm{R}_{4}=\mathrm{CH}_{3}, \mathrm{R}_{5}=\mathrm{H}\right)$ for quantitative analysis was obtained from each fraction by preparative HPLC (column, Develosil ODS-UG5 $(20 \mathrm{~mm}$ i.d. $\times 250 \mathrm{~mm}$, Nomura Chemical); solvent, $\mathrm{MeOH}-0.1 \%$ $\mathrm{HCOOH}$ ( $3: 2$ for $4,7: 3$ for 5 ); flow rate, $10 \mathrm{ml} /$ minute; detection, $220 \mathrm{~nm}$ ).

${ }^{13} \mathrm{C}$-labeled $\mathbf{4}$ and $\mathbf{5}$ were prepared from ${ }^{13} \mathrm{C}$-labeled $\mathbf{1}$ in a similar manner as described above.

Hydroxy Acid K (3)

Hydroxy acid K (3) was prepared by alkaline hydrolysis of $2(9.0 \mathrm{mg}, 0.016 \mathrm{mmol})$ using a similar method as for the preparation of hydroxy acids $\mathbf{4}$ and $\mathbf{5}$ from $\mathbf{1}$. The $\mathrm{CH}_{2} \mathrm{Cl}_{2}$ extract of the reaction mixture was used for bioconversion of $\mathbf{3}$ and $\mathbf{5}$ to $\mathbf{1 .}$ 
The product was methylated with diazomethane, and analyzed by GC-MS to confirm the structure of $\mathbf{3}$ under same conditions used for analysis of hydroxy acids $\mathbf{4}$ and $\mathbf{5}$. Hydroxy acid K (3) was obtained as a mixture of homologues with MW 370, 384, 398, and 412; and the content of hydroxy acid K with MW 384 which is the precursor of pamamycin-607 in total hydroxy acid $\mathrm{K}$ homologues was about $22 \%$ by GC-MS analysis.

The crude extract which contained $\mathbf{3}$ and $\mathbf{5}$ was purified by preparative TLC $\left(\mathrm{CHCl}_{3}-\mathrm{MeOH}(8: 2)\right)$, which gave 3 (Rf value $0.65 \sim 0.75,3.5 \mathrm{mg}, 59 \%$ ). The obtained fraction was used as reference compound for analyzing 3 in cultured materials.

${ }^{13} \mathrm{C}$-Labeled 3 was prepared from ${ }^{13} \mathrm{C}$-labeled 2 in a similar manner as described above.

De- $N$-methylhydroxy Acid L (7)

De- $N$-methylhydroxy acid L (7) was prepared by alkaline hydrolysis of de- $N$-methylpamamycin $6[9,10]$, which was isolated from cultured materials of the wild type strain, with a similar manner as for the preparation of hydroxy acids 4 and 5 using $10.0 \mathrm{mg}(0.017 \mathrm{mmol})$ of $\mathbf{6}$. The $\mathrm{CHCl}_{2}$ extract was used for bioconversion of $\mathbf{7}$ and $\mathbf{5}$ to $\mathbf{1}$.

${ }^{13} \mathrm{C}$-Labeled 7 was prepared from ${ }^{13} \mathrm{C}$-labeled 6 in a similar manner as described above. ${ }^{13} \mathrm{C}$-labeled $\mathbf{6}$ was obtained by a feeding experiment of $\left[2-{ }^{13} \mathrm{C}\right]$ acetate in $S$. alboniger.

\section{References}

1. Kondo S, Yasui K, Natsume M, Katayama M, Marumo S. Isolation, physico-chemical properties and biological activity of pamamycin-607, an aerial mycelium-inducing substance from Streptomyces alboniger. J Antibiot 41: 1196-1204 (1988)

2. Kondo S, Yasui K, Katayama M, Marumo S, Kondo T, Hattori H. Structure of pamamycin-607, an aerial myceliuminducing substance of Streptomyces alboniger. Tetrahedron Lett 28: 5861-5864 (1987)

3. Natsume M. Differentiation of aerial mycelia_-Pamamycins and calcium ion in Streptomyces alboniger. Actinomycetologica 13: 11-19 (1999)

4. Natsume M, Yasui K, Kondo S, Marumo S. The structures of four new pamamycin homologues isolated from Streptomyces alboniger. Tetrahedron Lett 32: 3087-3090 (1991)

5. Natsume M, Tazawa J, Yagi K, Abe H, Kondo S, Marumo S. Structure-activity relationship of pamamycins: Effects of alkyl substituents. J Antibiot 48: 1159-1164 (1995)

6. Natsume M, Honda A, Oshima Y, Abe H, Kondo S, Tanaka F, Marumo S. Roles of the dimethylamino group and macrodiolide ring of pamamycin-607 in its aerial myceliuminducing activity. Biosci Biotechnol Biochem 59: 17661768 (1995)

7. Hashimoto M, Kondo T, Kozone I, Kawaide H, Abe H, Natsume M. Relationship between response to and production of the aerial mycelium-inducing substances pamamycin-607 and A-factor. Biosci Biotechnol Biochem 67: 803-808 (2003)

8. Hashimoto M, Komatsu H, Kozone I, Kawaide H, Abe H, Natsume M. Biosynthetic origin of the carbon skeleton and nitrogen atom of pamamycin-607, a nitrogen-containing polyketide. Biosci Biotechnol Biochem 69: 315-320 (2005)

9. Kozone I, Chikamoto N, Abe H, Natsume M. De- $N$ methylpamamycin-593A and B, new pamamycin derivatives isolated from Streptomyces alboniger. J Antibiot 52: 329331 (1999)

10. Kozone I, Abe H, Natsume M. Effects of $N$-demethylation of pamamycins on aerial mycelium-inducing and growth inhibition activities. J Pesticide Sci 26: 149-153 (2001)

11. Surjan SR, Harold S. Oxidation of primary, secondary, and tertiary amines with neutral permanganate. A simple method for degrading amines to aldehydes and ketones. J Org Chem 32: 3129-3131 (1967)

12. Dewick PM. Medicinal Natural Products, 2nd ed. John Wiley \& Sons, Sussex, pp. 89-108 (2002)

13. Mitscher LA. Biosynthesis of the tetracycline antibiotics. J Pharm Sci 57: 1633-1648 (1968)

14. Vancurova I, Volc J, Flieger M, Neuzil J, Novotna J, Vlach J, Behal V. Isolation of pure anhydrotetracycline oxygenase from Streptomyces aureofaciens. Biochem J 253: 263-267 (1988)

15. Binnie C, Warren M, Butler MJ. Cloning and heterologous expression in Streptomyces lividans of Streptomyces rimosus genes involved in oxytetracycline biosynthesis. J Bacteriol 171: 887-895 (1989)

16. Dairi T, Nakano T, Aisaka K, Katsumata R, Hasegawa M. Cloning and nucleotide sequence of the gene responsible for chlorination of tetracycline. Biosci Biotechnol Biochem 59: 1099-1106 (1995)

17. Rhodes PM, Winskill N, Friend EJ, Warren M. Biochemical and genetic characterization of Streptomyces rimosus mutants impaired in oxytetracycline biosynthesis. J Gen Microbiol 124: 329-338 (1981)

18. Woo AJ, Strohl WR, Priestley ND. Nonactin biosynthesis: The product of nonS catalyzes the formation of the furan ring of nonactic acid. Antimicrob Agents Chemother 43: 1662-1668 (1999)

19. Smith WC, Xiang L, Shen B. Genetic localization and molecular characterization of the nonS gene required for macrotetrolide biosynthesis in Streptomyces griseus DSM40695. Antimicrob Agents Chemother 44: 1809-1817 (2000)

20. Hickey RJ, Tresner HD. A cobalt-containing medium for sporulation of Streptomyces species. J Bacteriol 64: 891-892 (1952) 
21. Grafe U, Schlegel R, Dornberger K, Ihn W, Ritzau M, Stengel C, Beran M, Gunther W. Isolation and structure elucidation of pamamycin-621, a new macrodiolide antibiotic from Streptomyces aurantiacus. Nat Prod Lett 3: 265-271 (1993) 